\title{
Karakterisasi Lorong Gua di Geosite Gua Pindul, Geopark Gunungsewu, Kabupaten Gunungkidul
}

Mohammad Ainul Labib ${ }^{1 *}$, Eko Haryono ${ }^{2,3}$, Haviz Damar Sasongko ${ }^{1}$, Romza Fauzan Agniy ${ }^{1}$, Ahmad Cahyadi ${ }^{2,3}$, Eko Bayu Dharma Putra ${ }^{1}$, Danardono $^{4}$, Roza Oktama ${ }^{1}$, Tjahyo Nugroho Adji ${ }^{2,3}$

Labib@mail.ugm.ac.id

\author{
${ }^{1}$ Karst Student Forum Fakultas Geografi Univeristas Gadjah Mada \\ ${ }^{2}$ Kelompok Studi Karst Fakultas Geografi Universitas Gadjah Mada \\ ${ }^{3}$ Departemen Geografi Lingkungan Fakultas Geografi Univeristas Gadjah Mada \\ ${ }^{4}$ Fakultas Geografi Universitas Muhamadiyah Surakarta
}

\begin{abstract}
ABSTRAK
Geopark Gunungsewu memiliki Geosite yang tersebar di Kabupaten Pacitan, Wonogiri, dan Gunungkidul. Salah satu geosite yang berkembang dengan cepat salah satunya terdapat di Kabupaten Gunungkidul, yaitu geosite Gua Pindul. Kajian ini bertujuan untuk menganalisis karakteristik lorong gua dan faktor-faktor yang mempengaruhi pembentukannya (speleogenesis) pada beberapa gua di geosite Gua Pindul dan sekitarnya. Metode yang digunakan yaitu dengan survei lapangan dengan melakukan pemetaan gua dan menganalisis bentuk lorong gua di lokasi kajian. Hasil kajian memperlihatkan pola lorong gua berupa curvilinear branchwork, sinuous passage, dan linier passage. Kenampakan lorong gua dipengaruhi oleh adanya kondisi tidak tertekan dan adanya air meteorik yang melarutkan batugamping, sehingga membentuk elliptical tube, keyhole, gorge-shaped passage, cupola, ceiling half tube, solutions notch, potholes, dan solutions pocket. Selain itu, adanya pengaruh kontrol struktural mempengaruhi arah perkembangan lorong gua sedangkan bentukan akibat adanya kontrol struktural berupa joint control passage, shaft, dan canyon.
\end{abstract}

Kata kunci : Geopark Gunungsewu, Gua Pindul, Lorong Gua, Speleogenesis

\section{PENDAHULUAN}

Kawasan Gunungsewu telah ditetapkan sebagai geopark yang telah diakui oleh dunia. Geopark Gunungsewu memiliki tiga lingkup kegiatan utama yaitu terkait dengan geodiversitas, biodiversitas, dan kebudayaan. Ketiganya memiliki arti penting bagi terbentuknya Geopark Gunungsewu. Geopark Gunungsewu memiliki geosite yang tersebar di Kabupaten Pacitan, Kabupaten Wonogiri, dan Kabupaten Gunungkidul. Kawasan Gunungsewu memiliki 30 situs geologi (geosite) dan 3 situs nongeologi. Geosite tersebut tersebar di Kabupaten Gunungkidul sebanyak 11 geosite dan 2 situs non geologi, Kabupaten Wonogiri terdapat 7 geosite, dan di Kabupaten Pacitan sebanyak 12 geosite dan 1 situs non geologi. Geosite ini merupakan warisan alam yang dilindungi dan dikembangkan menjadi objek dan daya tarik wisata yang diharapkan dapat meningkatkan perekonomian masyarakat lokal (Parno, 2018).

Kabupaten Gunungkidul memiliki beberapa gua yang menjadi geosite yaitu Gua Pindul, Gua Kalisuci, Luweng Jomblang, Luweng Cokro, Gua Ngingrong, Salah satu geosite yang paling banyak mengalami kunjungan wisata yaitu di geosite Gua Pindul (Suprayogi dkk., 2016; Jayanto dkk., 2016). Keberadaan gua ini berada di Basin Wonosari (Gambar 1), merupakan kawasan karst dengan batugamping. Batuan ini memiliki sifat mudah terlarut, sehingga terbentuk sistem perguaan. Hasil kajian yang telah dilakukan, memperlihatkan bahwa di geosite Gua Pindul memiliki beberapa mulut gua yang telah ditemukan antara lain sistem Gua Asri, Sistem Gua Candi, sistem Gua Suruh, Gua Tanding, Gua Pindul, Gua Sriti, Gua Glatik, dan Gua Baru (Haryono, 2014; Agniy, 2016; Cahyadi dan Agniy, 2016; Putra; 2018).

Gua-gua yang terdapat di geosite Gua Pindul memiliki karakteristik yang berbedabeda meskipun terdapat pada wilayah yang tidak terlalu luas. Hal ini menunjukkan pembentukan gua yang dikontrol oleh faktor yang berbeda-beda pula. Oleh karenanya diperlukan kajian yang mendalam khususnya terkait dengan speleogenesis gua-gua di Geosite Gua Pindul, untuk memperkaya khasanah tentang geodiversity lokasi tersebut, meningkatkan pemahaman tentang proses yang membentuk dan berlangsung serta dapat digunakan sebagai bahan pertimbangan pengembangan Geosite Gua Pindul di masa mendatang. Penelitian ini akan menganalisis karakteristik lorong gua di Geosite Gua Pindul serta menganalisis faktor-faktor yang membentuknya (speleogenesis). 
Paper ini merupakan edisi preprint dari makalah kami yang dipresentasikan pada Seminar Nasional Geografi III di Yogyakarta tanggal 2 November 2019 di Fakultas Geografi UGM

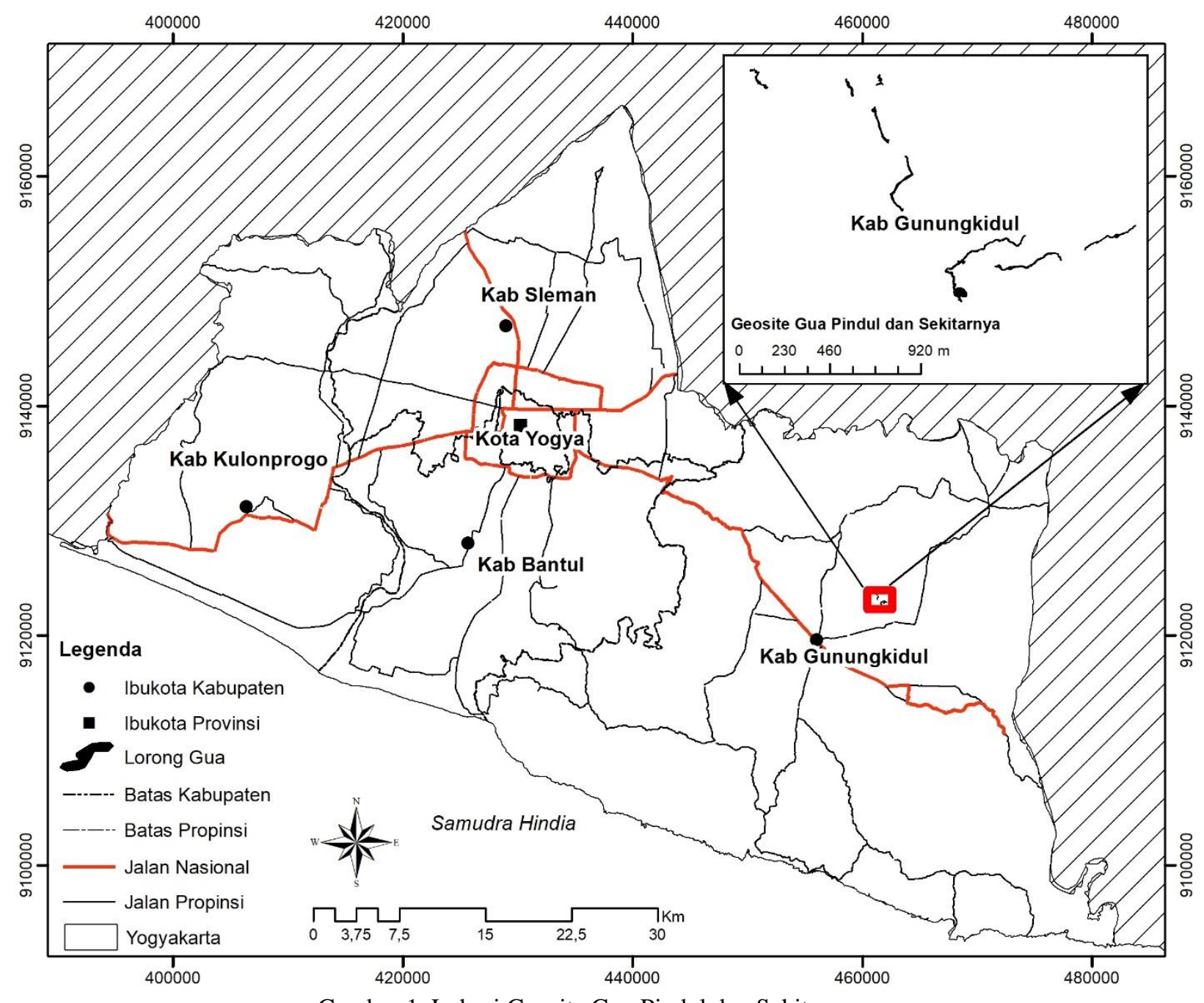

Gambar 1. Lokasi Geosite Gua Pindul dan Sekitarnya

\section{METODE}

Metode yang digunakan dalam penelitian ini adalah pemetaan gua dengan pengambilan data berupa panjang, lebar, tinggi, kemiringan lorong gua, arah centerline lorong gua, identifikasi dan inventarisasi ornament gua serta pengambilan dokumentasi berupa sketsa maupun foto lapangan. Selain itu, dilakukan pengambilan data tentang batuan dan struktur geologi seperti patahan, retakan dan perlapisan batuan. Data yang telah diperoleh selanjutnya dianalisis dengan pendekatan deskriptif untuk memberikan informasi mengenai pola, bentukan, dan keterhubungan antar lorong gua. Selain itu, dilakukan analisis terhadap hasil penelitian terdahulu di lokasi kajian. Data primer dan sekunder yang dikumpulkan kemudian digunakan untuk menganalisis karakteristik lorong gua dan faktor-faktor yang mempengaruhi terbentuknya. Gua yang dikaji dalam penelitian ini terdiri dari 8 sistem gua di Geosite Gua Pindul.

\section{HASIL DAN PEMBAHASAN}

Geosite Gua Pindul memiliki 8 sistem gua yaitu (1) Sistem Gua Asri, (2) Sistem Gua Candi, (3) Sistem Gua Suruh, (4) Sistem Gua Tanding, (5) Sistem Gua Pindul, (6) Sistem Gua Sriti, (7) Sistem Gua Glatik, dan (8) Sistem Gua Baru. Dilihat arah perkembangan lorong gua (center line) terdapat dua tipe. Lorong Sistem Gua Asri, Sistem Gua Candi, dan Sistem Gua Suruh memiliki kecendrungan arah lorong ke barat daya (SW-NE). Hal berbeda terjadi pada Sistem Gua Tanding, Sistem Gua Pindul, Sistem Gua Glatik, Sistem Gua Baru, dan Sistem Gua Sriti yang didominasi arah lorong ke barat laut (NW-SE). Arah perkembangan lorong gua di Geosite Gua Pindul dapat dilihat pada Gambar 2. 
Paper ini merupakan edisi preprint dari makalah kami yang dipresentasikan pada Seminar Nasional Geografi III di Yogyakarta tanggal 2 November 2019 di Fakultas Geografi UGM

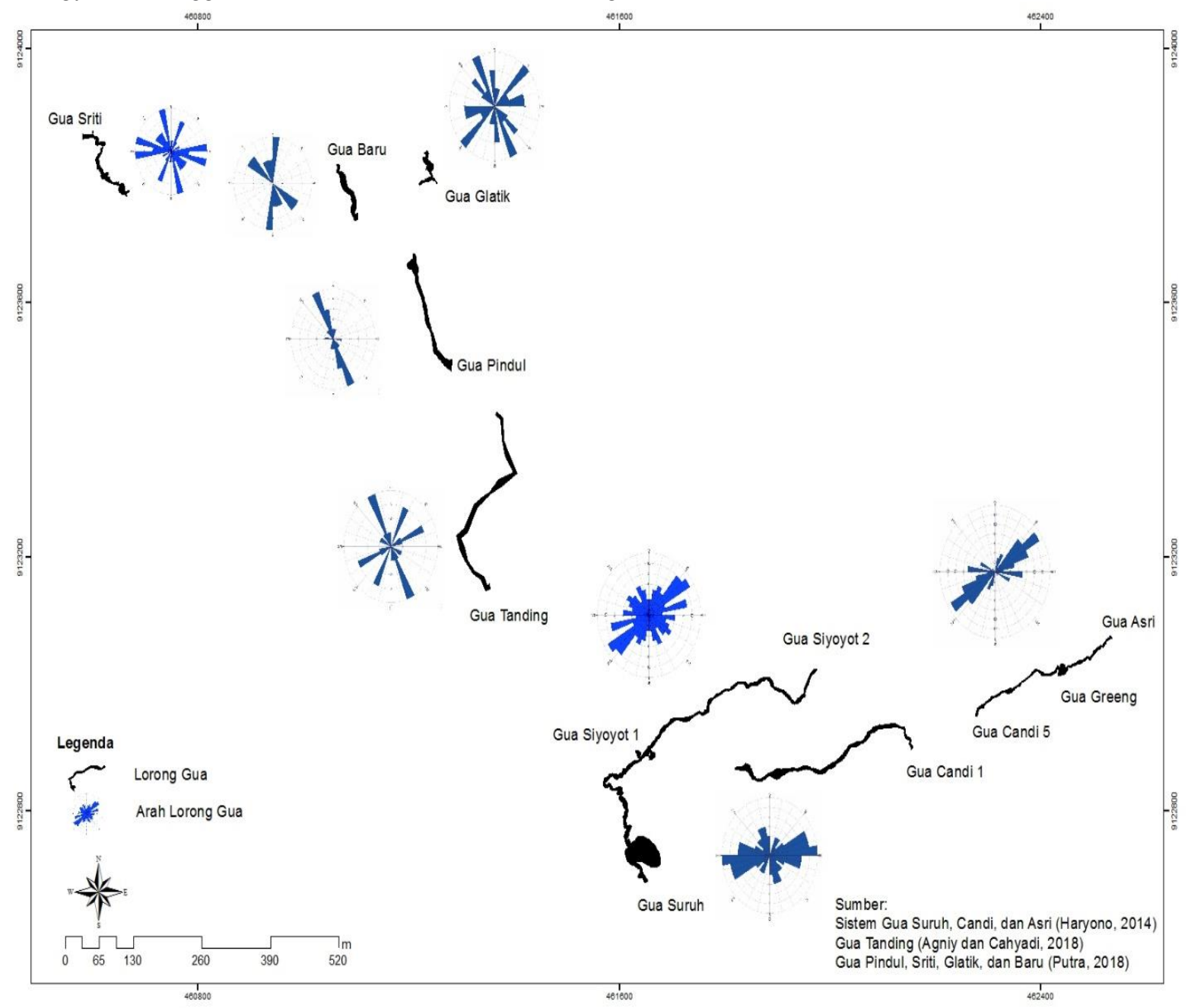

Gambar 2. Arah dan Lorong Gua di Geosite Gua Pindul

Gambar 2 menjelaskan mengenai pola arah perkembangan gua yang terdapat di Geosite Gua Pindul. Haryono (2014) menjelaskan bahwa lorong Gua Candi, Gua Suruh dan Gua Asri merupakan lorong yang memiliki pola curvilinear branchwork. Pola ini muncul karena terdapat banyak sinking stream dan atau cekungan-cekungan yang mengimbuh airtanah melalui mulut gua. Selain itu, kondisi lorong pada wilayah ini terkontrol oleh adanya bidang perlapisan.

Selain pola tersebut, menurut klasifikasi White (1988) pola yang terbentuk di wilayah kajian merupakan pola linear passage, sinuous passage, dan dapat pula keduanya terbentuk pada lorong gua tersebut. Kondisi linear passage dapat terlihat di Gua Asri, Gua Pindul, Gua baru, dan Gua Glatik. Kondisi ini umumnya terkontrol oleh kontrol struktural yang dominan pada lorong gua tersebut. Kondisi sinuous passage ditemui pada pola lorong Gua Candi, Gua Suruh, Gua Tanding, dan Gua Sriti. Bentukan sinuous passage diakibatkan adanya aliran sungai bawah tanah yang mempengaruhi kondisi lorong gua. Namun demikian, perkembangan sinuous passage dan linear passage dapat pula terbentuk dalam satu lorong gua seperti yang terdapat pada Gua Suruh dan Gua Candi.

Kondisi lorong gua di Gua Suruh, Gua Candi, dan Gua Asri menunjukkan adanya bentukan assymetric ellipse passage, elliptical tube, breakdown, shaft, chambers, canyon, rectangular passage, keyhole, gorgeshaped passage, joint control passage, ceiling half tube. Selain itu, pada penelitian sebelumnya Haryono (2014) menyebutkan adanya bentukan speleogen antara lain solutions notch, potholes, cups, dan solutions pocket. Bentukkan-bentukkan tersebut umumnya berada pada lorong yang berada pada kondisi tidak tertekan (unconfined).

Gambar 3 menjelaskan mengenai bentukan lorong gua, di mana pada Gua Baru dan Gua Tanding ditemukan adanya cupola (Gambar $3 c$ dan $3 b$ ), bentukan ini dapat terjadi akibat adanya arus udara yang melarutkan batuan tersebut akibat pengaruh dari aliran sungai bawah tanah. Bentukkan chamber (Gambar 3a) juga terdapat di Gua Baru dan Gambar 3d menunjukkan entrance Gua Pindul yang terbentuk karena proses struktural. 

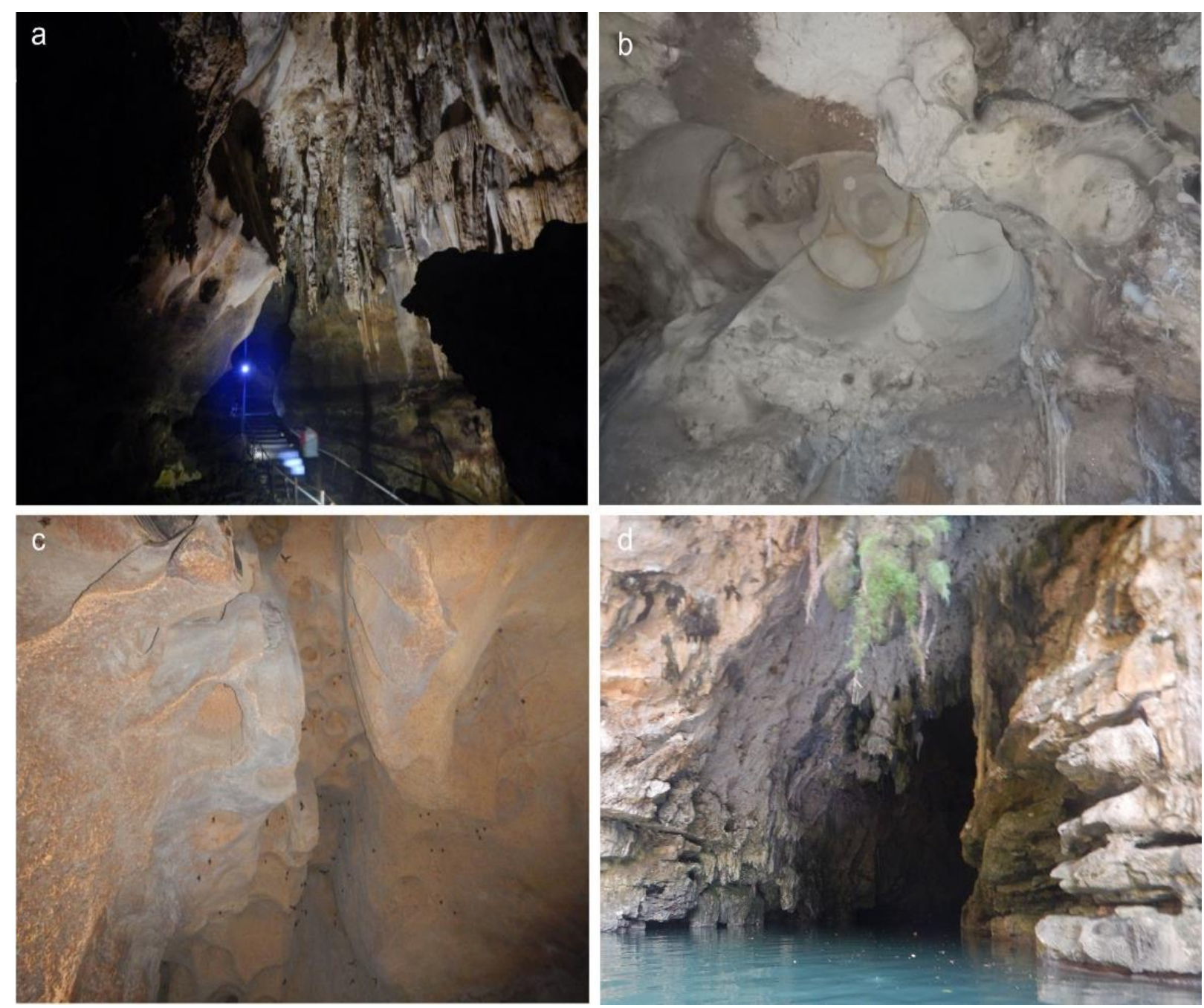

Gambar 3. Kondisi Lorong Gua di Geosite Gua Pindul

Keberadaan lorong gua juga dihiasi dengan adanya ornamen gua. Pada lorong Gua Suruh, Gua Asri, dan Gua Candi banyak terdapat ornamen gua berupa stalagtit dan stalagmit. Namun, kondisi ornament yang ada banyak ditutupi oleh endapan lumpur. Hal ini diakibatkan saat terjadi hujan, air akan memenuhi lorong gua dan aliran hujan membawa sedimen ke permukaan. Ornament gua yang bagus, terdapat di Gua Baru. Gua ini banyak terdapat stalagmit, stalagtit, dan flowstone yang besar. Kondisi ornament-ornament tersebut dapat dilihat pada Gambar 4. 

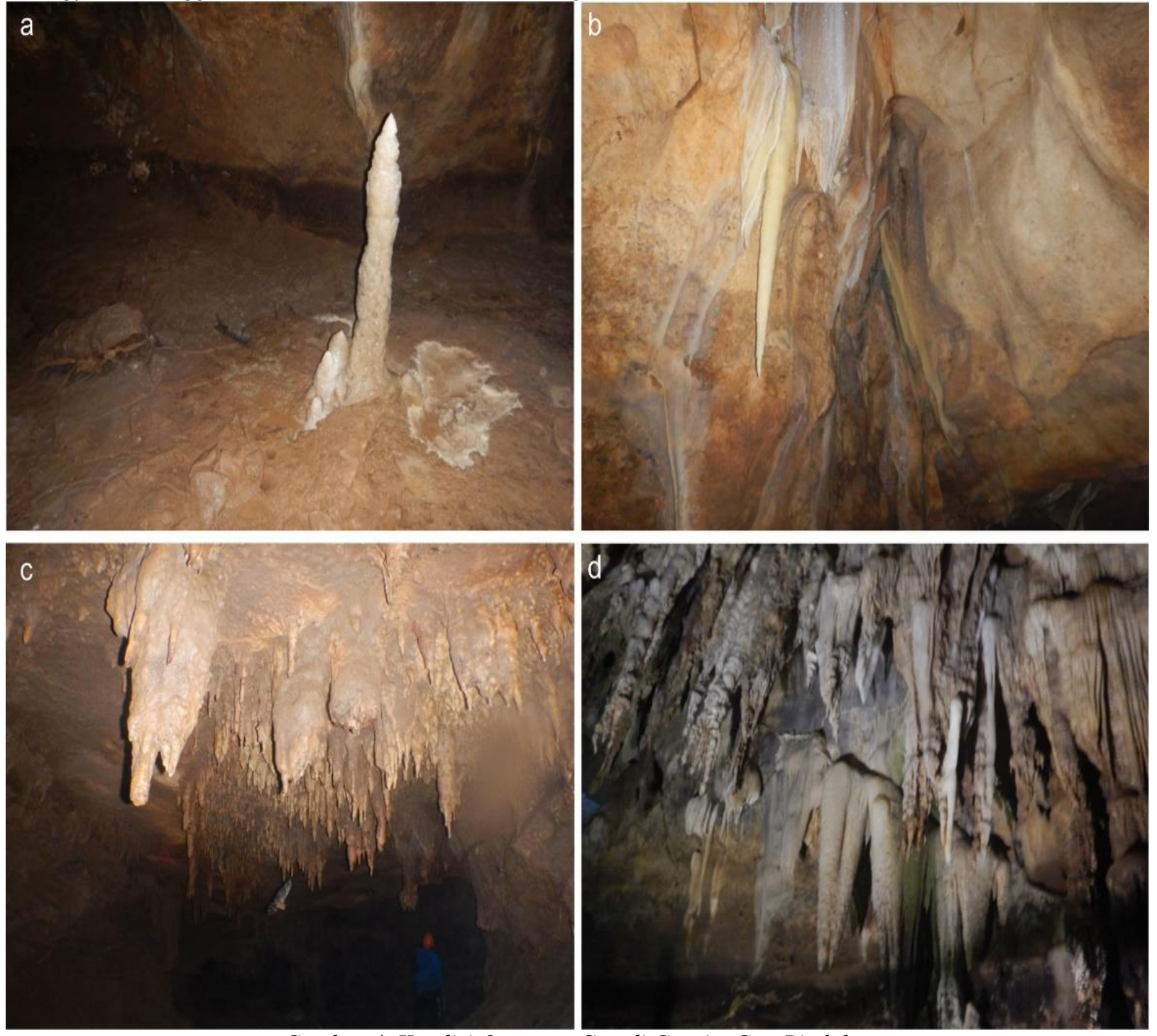

Gambar 4. Kondisi Ornamen Gua di Geosite Gua Pindul

Lorong-lorong gua yang ada di Geosite Gua Pindul memiliki beberapa keterkaitan. Gambar 5 menunjukkan bentukkan lorong gua di geosite Gua Pindul pada berbagai ketinggian. Hasil yang didapatkan menunjukkan bahwa pada ketinggian kurang lebih 179 - 174 mdpal memiliki lorong yang cenderung membentuk setengah lingkaran, ini terlihat di Gua Asri, Gua Candi, dan Gua Suruh. Namun ada pula yang membentuk rectangular pada ketinggian ini terdapat di gua candi. Pada ketinggian 172 174 mdpal membentuk pola canyon yang terdapat di gua asri dan candi. Keterhubungan lorong gua yang lain yaitu pada ketinggian lorong 172 - 160 mdpal lorong gua yang terbentuk berupa lorong fosil, tidak ditemukan aliran sungai bawah tanah namun terdapat endapan lumpur dan bongkahan batuan. Bentuk lorong gua cenderung rectangular dan canyon. Pada ketinggian lorong 159-156 terdapat aliran sungai bawah tanah, seperti yang terdapat di Gua Sriti. Perkembangan lorong gua pada ketinggian ini membentuk rectangular passage dan canyon passage. 
Paper ini merupakan edisi preprint dari makalah kami yang dipresentasikan pada Seminar Nasional Geografi III di Yogyakarta tanggal 2 November 2019 di Fakultas Geografi UGM

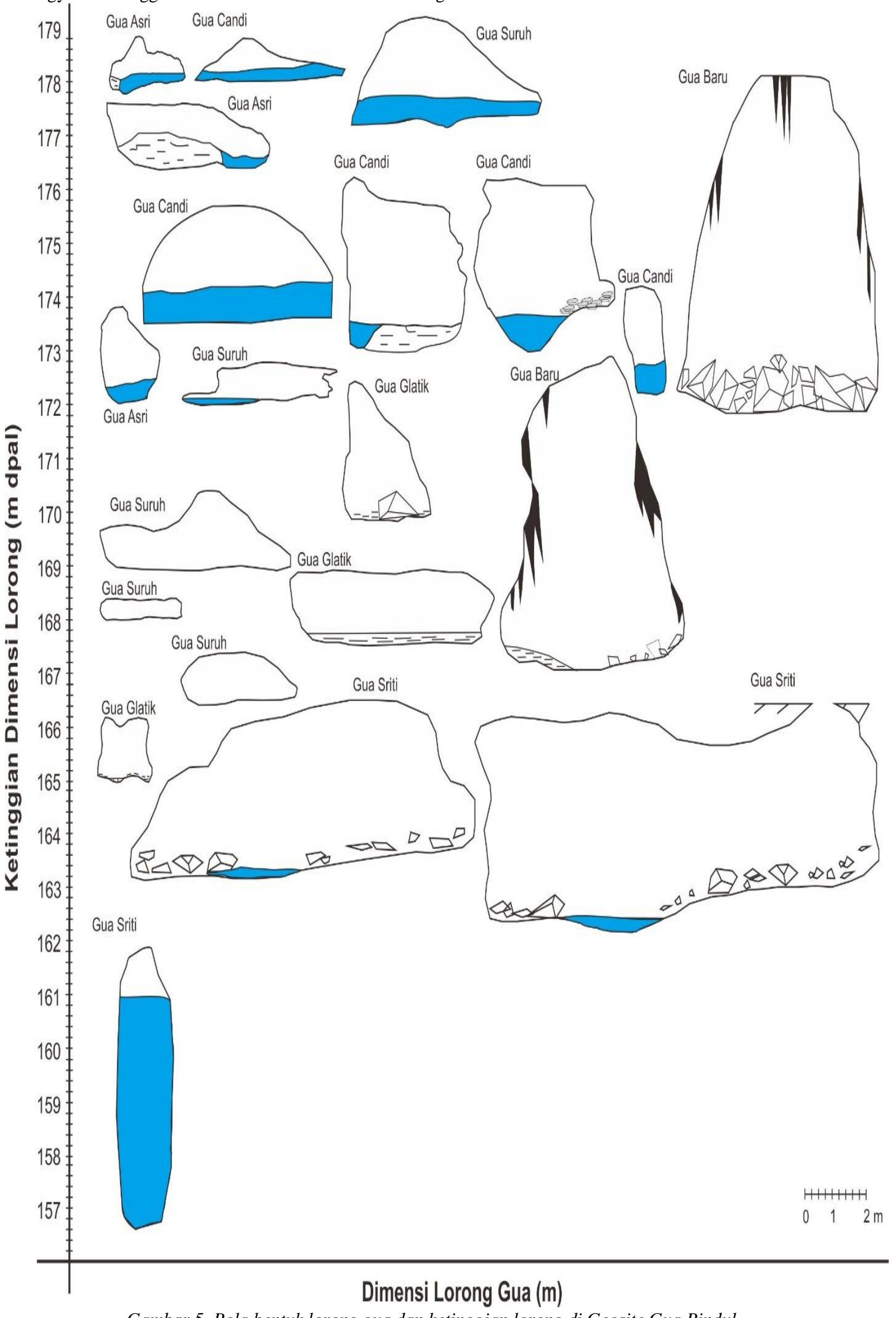

Gambar 5. Pola bentuk lorong gua dan ketinggian lorong di Geosite Gua Pindul 
Paper ini merupakan edisi preprint dari makalah kami yang dipresentasikan pada Seminar Nasional Geografi III di Yogyakarta tanggal 2 November 2019 di Fakultas Geografi UGM

Perkembangan lorong gua dapat ditentukan dengan melihat kondisi lorong gua. Ford dan Williams (2007) melihat perkembangan lorong gua dengan melihat sumber alirannya, dapat berasal dari air meteorik, airtanah dalam, atau dari sumber yang lain. Bentukan yang terjadi di geosite Gua Pindul menunjukkan bahwa air yang melarutkan batugamping berasal dari air meteorik. Hal ini terlihat dari kenampakan lorong gua yang ada, yaitu dengan ditemukannya sisa-sisa dari proses pelarutan seperti bentukan elliptical tube, keyhole, gorge-shaped passage, cupola, ceiling half tube, solutions notch, potholes, dan solutions pocket. Hasil kajian Haryono (2014) menjelaskan bahwa lorong gua pindul berada pada kondisi tidak tertekan (unconfined), sehingga proses pelarutan oleh air meteorik berjaan dengan intensif.

Perkembangan arah lorong gua saling terkait antara Gua Asri, Gua Candi, dan Gua Suruh yang mengarah ke barat daya (SW-NE). Namun demikian, arah aliran mengalami perubahan seperti hasil kajian Agniy (2016) di mana arah alirannya menuju ke Gua Pindul, yang selanjutnya dominasi perkembangan lorong gua mengarah ke barat laut (NW-SE). Hal seperti ini terlihat pada Gua Tanding, Gua Pindul, Gua Baru, Gua Glatik, dan Gua Sriti. Melihat kondisi lorong yang ada, perubahan ini diakibatkan oleh kontrol struktural yang terjadi di wilayah kajian.

Terkait dengan sistem perguaan yang terjadi, Agniy (2016), Cahyadi dan Agniy (2016) dan Agniy dkk (2017) memberikan gambaran bahwa lorong gua yang berada di sekitar Gua Pindul saling terkait. Namun demikian, terdapat pula lorong gua yang sistem alirannya tidak terkait yaitu, Gua Sriti, Gua Baru, dan Gua Glatik. Sistem Gua Sriti memiliki elevasi yang berbeda dengan sistem Gua Pindul. Gua Glatik berada di dekat outlet sistem Gua Pindul, namun hanya terdapat endapan lumpur dan bongkahan batuan, sedangkan Gua Baru merupakan gua yang terisolasi yang tidak terpengaruh adanya sungai bawah tanah. Gambar 5 menunjukkan bahwa aliran sungai bawah tanah yang ada hanya terdapat pada sistem Gua Pindul, sedangkan pada Gua Glatik, Gua Sriti, dan Gua Baru tidak saling terkait. Haryono (2014) menjelaskan adanya tiga zona yang berkembang yaitu zona vadose, zona ephifreatik, dan zono freatik. Pada Gua Baru berkembang zona vadose, pada Gua Glatik berkembang zona Vadose dan epifreatik, pada Gua Sriti berkembang tiga zona tersebut.

\section{KESIMPULAN}

Hasil kajian memperlihatkan pola lorong gua berupa curvilinear branchwork, sinuous passage, dan linier passage. Kenampakan lorong gua dipengaruhi oleh adanya kondisi tidak tertekan dan adanya air meteorik yang melarutkan batugamping sehingga membentuk elliptical tube, keyhole, gorge-shaped passage, cupola, ceiling half tube, solutions notch, potholes, dan solutions pocket. Selain itu, adanya pengaruh kontrol struktural mempengaruhi arah perkembangan lorong gua, sedangkan bentukan akibat adanya kontrol struktural berupa joint control passage, shaft, canyon.

\section{UCAPAN TERIMAKASIH (Acknowledgement)}

Penelitian ini dibiayai oleh penelitian hibah payung dengan skema Hibah Penelitian Dasar Unggulan Perguruan Tinggi (PDUPT) tahun 2019 Universitas Gadjah Mada. Kami juga mengucapkan banyak terima kasih kepada semua pihak yang terkait dengan berjalannya penelitian ini.

\section{REFERENSI}

Agniy, R.F. 2016. Kajian Hidrogeologi Karst Sistem Gua Pindul, Kecamatan Karangmojo, Kabupaten Gunungkidul. Skripsi tidak diterbitkan. Yogyakarta: Fakultas Geografi Universitas Gadjah Mada.

Agniy, R.F.; Cahyadi, A. dan Nurkholis, A. 2017. Analisis Karakteristik Akuifer Karst dengan Uji Perunutan dan Pemetaan Gua. Proceeding, Kongres \& Pertemuan Ilmiah Tahunan Ke-2 Perhimpunan Ahli Airtanah Indonesia (PIT-PAAI) 13 - 15 September 2017, Yogyakarta

Cahyadi, A. dan Agniy, R.F. 2016. Analisis Breakthrough Curve untuk Karakterisasi Pelorongan di Sistem Sungai Bawahtanah Pindul Kabupaten Gunungkidul. Prosiding Pertemuan Ilmiah Tahunan Ke-1 Perhimpunan Ahli Airtanah Indonesia (PIT-PAAI) Bandung, 16 - 17 November 2016, Halaman 375 -385.

Ford, D. and Williams, P. 2007. Karst Hydrogeology and Geomophology. England: British library

Haryono, E. 2014. Speleogenesis Gua Pindul dan sekitarnya. Laporan Penelitian. Yogyakarta: Fakultas Geografi UGM.

Jayanto, G.D.; Suprayogi, S.; Purnama, S. dan Cahyadi, A. 2016. Prospeksi Kawasan Pindul sebagai Kampus Lapangan Hidrologi dan Geomorfologi Karst. Dalam Suprayogi, S.; Purnama, S.; Cahyadi, A. dan Fatchurohman, H. 2016. Hidrologi dan Kepariwisataan Kawasan Karst Gua Pindul, Kabupaten Gunungkidul. Yogyakarta: Badan Penerbit Fakultas Geografi.

Nurkholis, A.; Haryono, E.; Cahyadi, A.; Agniy, R.F. 2017. Variasi Spasial dan Temporal Sifat Aliran untuk Karakterisasi Akuifer Karst Sistem Pindul, Kabupaten Gunungkidul. Proceeding, Kongres \& Pertemuan 
Paper ini merupakan edisi preprint dari makalah kami yang dipresentasikan pada Seminar Nasional Geografi III di Yogyakarta tanggal 2 November 2019 di Fakultas Geografi UGM

Ilmiah Tahunan Ke-2 Perhimpunan Ahli Airtanah Indonesia (PIT-PAAI) 13 - 15 September 2017, Yogyakarta.

Parno. 2018. Gunungsewu Unesco Global Geopark. Jakarta: Badan Pengembangan dan Pembinaan Bahasa Kemendikbud.

Putra, E.B.D. 2018. Kajian Daya Dukung Wisata Gua Dengan Pendekatan Parameter Iklim Mikro Gua (Studi Kawasan Wisata Gua Pindul, Desa Bejiharjo, Gunungkidul, DIY). Thesis tidak diterbitkan. Yogyakarta: Sekolah Pascasarjana Universitas Gadjah Mada.

Suprayogi, S.; Cahyadi, A. dan Agniy, R.F. 2016. Urgensi Pengelolaan Kawasan Karst Gua Pindul, Kecamatan Karangmojo, Gunungkidul. Dalam Suprayogi, S.; Purnama, S.; Cahyadi, A. dan Fatchurohman, H. 2016. Hidrologi dan Kepariwisataan Kawasan Karst Gua Pindul Kabupaten Gunungkidul. Yogyakarta: Badan Penerbit Fakultas Geografi.

White, B, W. 1988. Geomorphology and Hydrology of Karst Terrains. New York. Oxford University Press. 